\title{
Woody Encroachment Extent and Its Associated Impacts on Plant and Herbivore Species Occurrence in Maswa Game Reserve, Tanzania
}

\author{
Houssein S. Kimaro ${ }^{1,2}$, Ayoub M. Asenga ${ }^{1}$ Linus Munishi $^{1}$ \& Anna C. Treydte ${ }^{1,3}$ \\ 1 Department of Sustainable Agriculture and Biodiversity Conservation, School of Life Sciences and \\ Bioengineering, The Nelson Mandela African Institution of Science and Technology, Arusha, Tanzania \\ ${ }^{2}$ Department of Wildlife Management, College of African Wildlife Management, Mweka (CAWM) \\ ${ }^{3}$ Agroecology in the Tropics and Subtropics, Hans Ruthenberg Institute, University of Hohenheim, Stuttgart, \\ Germany \\ Correspondence: Houssein Samwel Kimaro, Department of Sustainable Agriculture and Biodiversity \\ Conservation, School of Life Sciences and Bioengineering, The Nelson Mandela African Institution of Science \\ and Technology, P.O Box 447-Arusha, Tanzania. Tel: 255-6-5793-1430. E-mail: kimaroh@nm-aist.ac.tz; \\ kimaro.martin@yahoo.com
}

Received: April 6, 2019

Accepted: April 20, 2019

Online Published: July 26, 2019

doi:10.5539/enrr.v9n3p63

URL: https://doi.org/10.5539/enrr.v9n3p63

\begin{abstract}
Habitat degradation caused by woody plant encroachment has been a common phenomenon in savanna ecosystems. An increasing woody plant cover in open grassland reduces grazing grounds and, consecutively, impacts mammalian herbivores, but structural changes and their associated impact have rarely been assessed and quantified. We analyzed the extent of woody plant encroachment via remote sensing and used transects and plots to assess encroaching woody plant species and their associated impacts on herbaceous plant and herbivore species in Maswa Game Reserve, Tanzania. We found that woody plant cover had increased by $0.5 \%$ to $2.6 \%$ per annum over the last thirty years, while in other parts of the park it has decreased by $0.5 \%$ to $1.5 \%$ per annum. Acacia drepanolobium was the dominant encroaching woody species, and the number of stems in heavily encroached sites was seven times and three times higher than in open grassland and at medium encroached sites, respectively. In encroached plots, grazer and mixed feeder species occurrence were reduced while the presence of browser species was slightly elevated. Furthermore, our findings show that bare ground cover is positively correlated with an increase of woody plant cover. Additionally, the number of herbaceous species slightly increased with the increase of woody plant encroachment, while the herbaceous cover was negatively correlated with the increase of woody plant cover. We suggest that fire regimes should be taken up to suppress the ongoing encroachment processes while strongly encroached sites might need mechanical intervention to control dense vegetation. This emphasis is on fire, particularly prescribed fire as a management tool of vegetation in Savanna ecosystem. We conclude that, woody plant encroachment is driven by different factors such as fire, mega-herbivores and topology that may interactively trigger woody plant encroachment in Savanna ecosystem.
\end{abstract}

Keywords: Remote Sensing, Acacia Drepanolobium, Grassland, Serengeti Ecosystem, Herbivores, Fire, Africa

\section{Introduction}

Habitat degradation caused by woody plant encroachment has been a common phenomenon in savanna ecosystems (Archer et al., 2017). During this process, thicket species, shrubs and trees increase in density and cover encroaching into open grassland (Van Auken, 2000; Ward, 2005). New thickets have been formed in savanna and woodland areas as a result of woody plant encroachment (Khavhagali \& Bond, 2008). Generally, some areas experience successive transformation from grassland to woodland and, finally, forest, a phenomenon referred to as forest colonization (Bond, 2008).

Increased woody biomass normally comprises thorny and unpalatable species (Kgosikoma \& Mogotsi, 2013), outcompeting and or suppressing palatable woody and herbaceous species (Ward, 2005). Bush encroachment decreases herbaceous production and biomass, species richness and diversity (Van Auken, 2009; Khavhagali \& Bond, 2008). As herbaceous production and biomass decreases, native plant seed rain becomes reduced, and natural storage of dormant seeds within the soil decreases with time (Saatkamp, Poschlod, \& Venable, 2014). 
When native species seeds are lost from the soil seed banks, the land loses its resilience that had ensured native species persistence in the long run (Yachi \& Loreau, 1999). These changes may negatively affect grazing activities by reducing the quality and quantity of grazing land resources (Yachi \& Loreau, 1999), consecutively species community assemblages as well as their associated ecosystem services to local communities. In Africa, woody cover has increased by 7.5 million $\mathrm{km}^{2}$ (Venter, Cramer, \& Hawkins, 2018). This increase has in some areas decreased rangeland carrying capacity, i.e., quantity and quality (Karuaera, 2011; Venter et al., 2018), changing the vegetation structure from open grassland to scrubland. As encroached sites differ in plant community composition and/or structure due to intra and or inter-specific competition, there is a need to assess and quantify structural changes (Jurena \& Van Auken, 1998; Venter et al., 2018) that may influence future woody plant encroachment of the site.

The impact of woody plant encroachment on herbaceous plants can be negative, neutral or positive, and depends on the abundance, growth form, root arrangements and canopy architecture of the encroaching woody plant (Archer, 1995; Eldridge et al., 2011). In North America, for instance, a woody plant increase in grassland has changed the plant community composition and reduced plant species richness (Eldridge et al., 2011; Ratajczak, Nippert, \& Collins, 2012). Contrary to this finding, other studies have reported increases of herbaceous species, i.e. shade-loving herbaceous species under canopy of trees (Treydte, Heitko, Prins, \& Ludwig, 2007; Wonga \& Wilson, 1980), and/or defense mechanisms against grazers as they grow under thorny woody shrubs (Dharani, 2006).

Further, woody plant encroachment can lead to substantial changes in herbivore community assemblages in savanna ecosystems. Low herbaceous species cover due to woody plant encroachment can decrease grazer species abundance and increase browsers (Smit \& Prins, 2015). Encroached sites may also create hunting cover for predators, representing a landscape of fear for medium-sized herbivores, which might repel the latter and only attract mega-herbivore species that can feed on the woody component (Smit \& Prins, 2015). Hence, we expect that medium-sized herbivore species, contrary to mega-herbivores, will be found less frequently with increasing encroachment intensity.

Maswa Game Reserve located on the western side of the two major world heritage sites (Serengeti National Park and Ngorongoro Conservation Area) is an ecologically essential area of the Serengeti ecosystem in Tanzania (Makacha, Msingwa, \& Frame, 1982). Its open grassland areas have been severely encroached mainly by Acacia drepanolobium in the recent years, but locations and the extent of these areas have not been assessed. Maswa is an important refuge and maternal site for wildebeest and other herbivore species in the Serengeti ecosystem (TAWA, 2018). With increasing woody plant encroachment (Niboye, 2010) in open grassland consecutively affecting forage access by the herbivores, it raises concern over the rangeland quality and herbivores welfare in the Serengeti ecosystem.

The objective of this study was to assess the extent of increase in woody cover and to characterize woody species composition, structure and herbaceous layer as well as to assess wild herbivore usage in areas of different encroachment categories.

\section{Materials and Methods}

\subsection{Study Site}

The study was conducted from March to July 2018 within Maswa Game Reserve (34 $35^{\prime} 49.6^{\prime \prime}$ E and 3017'3.7' S; Figure 1), an area occupying 2,200 $\mathrm{km}^{2}$ within the Serengeti ecosystem in Tanzania (TAWA, 2018; URT, 2017a). The study area is an important shield for the Serengeti National Park and Ngorongoro Conservation Area (Chami, 2018; URT, 2017b) since it offers maternity ground for wildebeest during the dry season and represents a crucial resting ground for the great wildebeest migration in the Serengeti-Maasai Mara ecosystem (TAWA, 2018). Main wildlife species present include giraffe (Giraffa camelopardalis), wildebeest (Connochaetes taurinus), waterbuck (Kobus ellipsiprymnus), African elephants (Loxodonta africana), buffalo (Syncerus caffer), impala (Aepyceros melampus), topi (Damaliscus korrigum), zebra (Equus quagga), baboon (Papio anubis), jackal (Canis aureus), hyena (Crocuta crocuta), leopard (Panthera pardus), lion (Panthera leo) and a variety of antelopes and bird species. (TAWA, 2018; URT, 2017a). Vegetation of the area includes Acacia woodland, thorn scrub, short grass plains, grassland areas and Kopjes (URT, 2017b). Maswa Game Reserve, just like other parts of the Serengeti ecosystem have two wet seasons, i.e., the short rains and the long rains, with average annual rainfall of $600-900 \mathrm{~mm}$ (Bartzke et al., 2018; URT, 2017b) and average annual temperatures of $9{ }^{\circ} \mathrm{C}-22^{\circ} \mathrm{C}$ in the winter season, and $18^{\circ} \mathrm{C}$ $31^{\circ} \mathrm{C}$ in summer (URT, 2017b). Vegetation changes from grassland to thicket areas have long been observed and reported in the Maswa Game Reserve (Niboye, 2010). The main ethnic group of the area includes pastoralists, farmers and hunters, mainly from the Sukuma tribe (Chami, 2018; Jangu, 2012). 


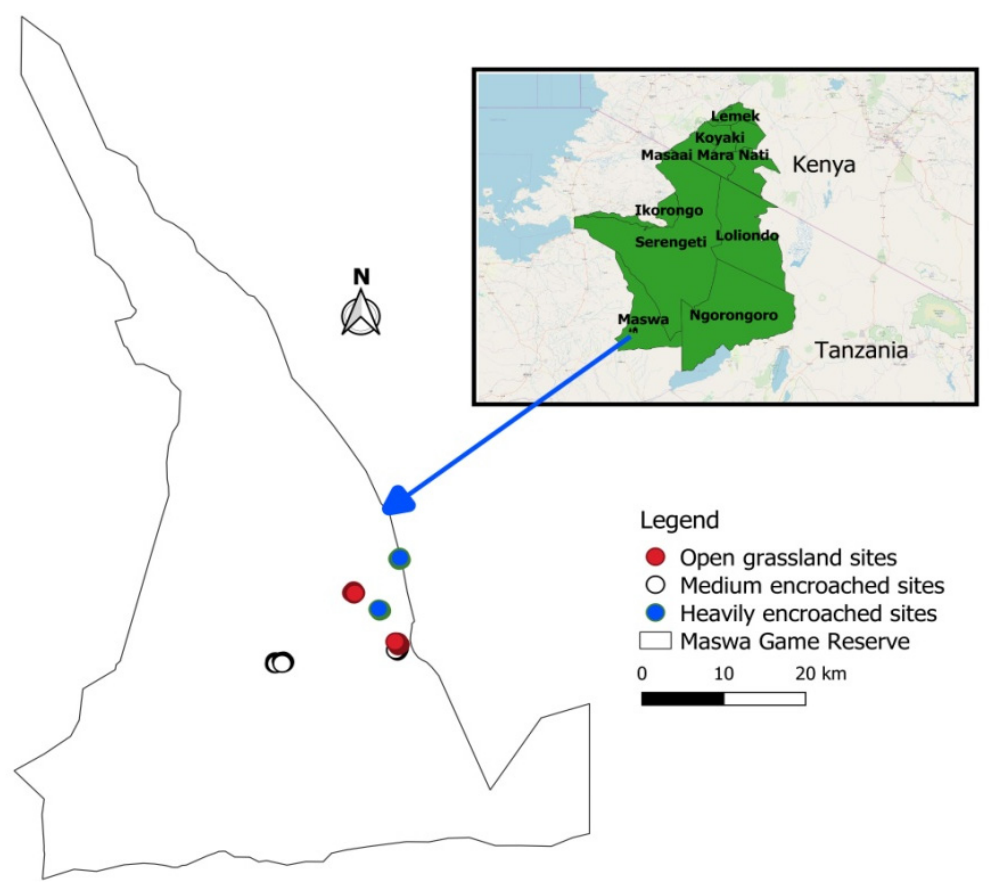

Figure 1. Study sites in Maswa Game Reserve, northern Tanzania. Open grassland = sites with no encroachment, medium encroached sites $=$ sites with less than $50 \%$ of woody cover, heavily encroached sites $=$ sites with more than $50 \%$ of woody cover

\subsection{Sampling Strategy}

Forty-four $400 \mathrm{~m}$ long transects, each containing four plots, summing up to a total of 192 plots, were established in the study site (Buckland, Borchers, Johnston, Henrys, \& Marques, 2007). Transects were placed 50m apart from each other, and in total, we covered $96,000 \mathrm{~m}^{2}$ across all six surveyed sites. Transect layouts were stratified by encroachment categories, which were defined by visual assessment (Beltrán, 2015). Sixteen transects, comprised of 64 plots, were located within each established encroachment category, i.e., (1) heavily encroached $(>50 \%$ bush cover), (2) medium encroached ( $<50 \%$ bush cover), (3) no encroachment (no bush cover but only sparse trees and continuous grass cover) (Beltrán, 2015). In each of the three encroachment categories, direct and indirect (e.g. dung heaps, foot print and forage activity) occurrence of large mammals (carnivores, browsers and grazers) were assessed within four $10 \times 10 \mathrm{~m}$ plots (Bacaro et al., 2015), located every $100 \mathrm{~m}$ along the transect (Keeping \& Pelletier, 2014). We did not quantify numbers but recorded wildlife occurrence as present or absent data only for each species observed in a plot. The dung, footprint, and forage activity reflected the relative use and or access of the encroachment category by herbivores (Pfeffer, 2016). Within each plot, tree species were identified and their structure (canopy diameter, stem diameter at $1 \mathrm{~m}$ height, seedling occurrence, height) recorded and bare ground cover was visually estimated (Monteiro, Burak, Cunha, \& Passos, 2018). Multi-stemmed woody plants were considered as separate individuals if they were $>40 \mathrm{~cm}$ apart (Tefera, Dlamini, \& Dlamini, 2008). Data obtained were used in the analysis of abundance, structure and composition of woody plant species. A plot of $1 \times 1 \mathrm{~m}$ in size was established at the NE corner within each of the $10 \times 10 \mathrm{~m}$ plot, and herbaceous vegetation cover was visually estimated as percentage cover of each identified plant species (Damgaard, 2014). The $10 \times 10 \mathrm{~m}$ plot were categorized into lower slope plot $(\mathrm{N}=96)$ and upper slope plots $(\mathrm{N}=96)$.

\subsection{Spatio-Temporal Changes in Vegetation Cover}

Land-cover change in Maswa Game Reserve was done using 30m resolution Landsat images from the USGS (www.glovis.usgs.gov). We used a combination of TM for the year 1986, ETM+ for 2002 and OLI for 2018. The reserve falls at the intersection of two scenes of images (path/row 169/062 and 170/062). Thus, selected images were based on closeness of their acquisition date. Changes were mapped by classifying images into nine classes adopted from previous studies by Tsegaye et al. (2010) and Abate \& Angassa (2016) as follows: (1) Grassland, with $<10 \%$ cover of sparse woody plants and dominated with continuous herbaceous cover. (2) Shrubby grassland, Grassland sites with scattered shrubs having cover between $15 \%$ and $30 \%$ multi-stem woody plants generally 
below $2 \mathrm{~m}$. (3) Shrubland, with $>50 \%$ cover of multi-stem woody plants generally below 2 m. (4) Woodland, woody plants generally taller than $5 \mathrm{~m}$ at densities $<50 \%$ canopy cover height including areas with trees mixed with shrubs. (5) Forest patch, single-stem woody plants generally taller than $5 \mathrm{~m}$ and at density $>60 \%$ canopy cover. (6) Bare ground, areas with no vegetation such as exposed rock outcrops and sand. (7) Cultivation, areas where crop growing is practiced seasonally and permanently. (8) Settlement, urban and rural settlements within the study area. (9) Water, mostly permanent water sources.

Processing and classification of images followed the procedures recommended by Exelis Visual Information Solutions (2015) using ENVI 5.3. Training areas were digitized using high resolution imagery in Google Earth (Kuemmerle et al., 2010) and previous vegetation maps (Estes et al., 2008). Furthermore, a total of 356 ground truth points were collected from the field where 256 were used for image classification and 100 for validation. Ground truth points were gathered using knowledge from local people and experts who are familiar with the area from earlier times. The overall accuracy of the classification was conducted using a confusion error matrix where the user's accuracy (UA), producer's accuracy (PA), and statistical Kappa coefficient of each class were computed (Congalton \& Green, 1999; Table 1).

\subsection{Statistical Analysis}

Analyses were performed in R, Wilcoxon test and one way ANOVA (v.3.4.1 The R Foundation for Statistical Computing 2017) and PAleontological STatistics (PAST) version 3.20 (Hammer, Harper, \& Ryan, 2001). Data were checked for normality. Kruskal-Wallis tests were used to test whether the number of trees, canopy diameter, average stem diameter, and number of saplings differ across encroachment intensity. A Dunn's post hoc analysis was performed to test significant differences across distribution/median. The test for difference of tree heights across encroachment categories was done using T-test at $95 \%$ confidence interval. A Kendall tau correlation that handles ties for non-normalized data was used to test for the correlation between the number of trees with sapling, canopy diameter and average stem size.

\section{Results}

\subsection{Woody Plant Cover Change}

Woody cover from 1986 to 2016 decreased annually by $1.55 \%$ in the western and southern areas of Maswa Game Reserve while the middle of the Maswa Game Reserve experienced an average annual increase in woody cover from $1.55 \%$ to $2.63 \%$ (Figure 2 ). The shrubland increased by $433.9 \mathrm{~km}^{2}(19.7 \%$ of the current reserve area size) from 1986 to 2018 (Table 2). Generally, the increase of woody cover was associated with an expansion of scrub land and shrubby grassland (Table 2).

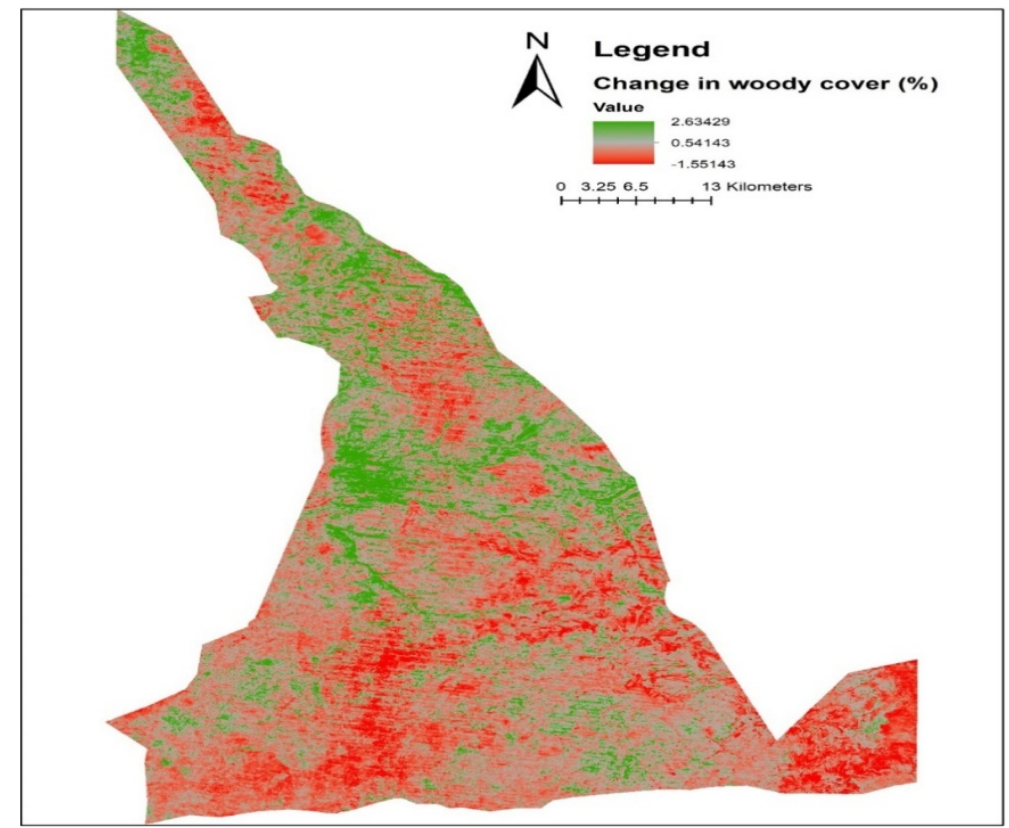

Figure 2. Average annual percentage change in woody cover from 1986 to 2016 in Maswa Game Reserve, Tanzania 
Table 1. Accuracy assessments for the 1986, 2002, and 2018 land cover maps

\begin{tabular}{|c|c|c|c|c|c|c|}
\hline \multirow{2}{*}{ Land cover } & \multicolumn{2}{|c|}{1986} & \multicolumn{2}{|c|}{2002} & \multicolumn{2}{|c|}{2018} \\
\hline & $\mathrm{PC}(\%)$ & UA $(\%)$ & $\mathrm{PC}(\%)$ & UA $(\%)$ & $\mathrm{PC}(\%)$ & UA $(\%)$ \\
\hline GL & 97.85 & 98.24 & 96.86 & 87.19 & 96.62 & 97.67 \\
\hline $\mathrm{SG}$ & 77.5 & 73.08 & 83.71 & 91.43 & 94.78 & 90.83 \\
\hline SL & 70.45 & 66.45 & 73.17 & 82.07 & 92.58 & 96.13 \\
\hline WL & 95.2 & 85.62 & 94.03 & 87.89 & 67.84 & 75.87 \\
\hline FP & 69.56 & 73.18 & 58.16 & 91.39 & 74.92 & 100 \\
\hline BG & 96.55 & 57.14 & 59.46 & 80.04 & 59.55 & 98.76 \\
\hline $\mathrm{C}$ & 71.06 & 88 & 54.71 & 67.97 & 78.52 & 57.27 \\
\hline $\mathrm{S}$ & 67.97 & 80.1 & 53.43 & 58.42 & 68.51 & 86.04 \\
\hline W & 97.85 & 100 & 74.5 & 100 & 99.4 & 100 \\
\hline Over all accuracy $(\%)$ & & 87.98 & 88.46 & & & 92.54 \\
\hline Kappa coefficient & & 0.82 & 0.84 & & & 0.89 \\
\hline
\end{tabular}

Table 2. Vegetation cover (in $\mathrm{km}^{2}$ and \%) changes in Maswa Game Reserve, Tanzania, from 1986 to 2018

\begin{tabular}{|c|c|c|c|c|c|c|}
\hline Class & 1986 & $\%$ & 2002 & $\%$ & 2018 & $\%$ \\
\hline Bare ground & 0.06 & 0.00 & 0.00 & 0.00 & 0.01 & 0.00 \\
\hline Cultivation & 38.02 & 1.32 & 50.32 & 1.75 & 87.77 & 3.05 \\
\hline Forest & 76.99 & 2.68 & 17.05 & 0.59 & 24.60 & 0.86 \\
\hline Grassland & 350.82 & 12.19 & 207.03 & 7.20 & 234.50 & 8.15 \\
\hline Settlement & 7.04 & 0.25 & 19.10 & 0.66 & 18.58 & 0.65 \\
\hline Shrubby grassland & 488.78 & 16.99 & 818.69 & 28.45 & 490.21 & 17.04 \\
\hline Shrubland & 277.08 & 9.63 & 322.95 & 11.22 & 710.95 & 24.71 \\
\hline Water & 0.00 & 0.00 & 0.01 & 0.00 & 0.90 & 0.03 \\
\hline Woodland & 1638.89 & 56.95 & 1442.52 & 50.13 & 1310.17 & 45.53 \\
\hline Total & 2877.68 & 100.00 & 2877.68 & 100.00 & 2877.68 & 100.00 \\
\hline
\end{tabular}

\subsection{Encroaching Woody Plant Species}

Across all encroachment categories, we encountered a total of 818 stems of Acacia drepanolobium, Acacia seyal and Commiphora africana. On average, encroachment categories differed significantly in stem numbers, with the heavily encroached sites having $1102 \pm 82$ stems ha $^{-1}$ (Table 3), with A. drepanolobium dominating with (72\%), while $C$. africana comprised 28\%. Medium encroached sites had $327 \pm 39$ stems ha $^{-1}$ (Table 3), with $A$. drepanolobium dominating with $44 \%$, followed by $A$. seyal with (33\%) and $C$. africana with $23 \%$. Open grassland sites had $157 \pm 30$ stems ha $^{-1}$ (Table 3), with A. drepanolobium contributing $73 \%$ and C. africana $27 \%$.

Table 3. Average $( \pm \mathrm{SE})$ number of stems per hectare of the dominant tree species and associated encroaching tree traits across three encroachment categories in Maswa Game Reserve. Open grassland = sites with no encroachment, medium encroached $=$ sites with less than $50 \%$ of woody cover, heavily encroached $=$ sites with more than $50 \%$ of woody cover. Different letters show significant differences as per Dunn's post hoc test at the $95 \%$ confidence level

\begin{tabular}{|c|c|c|c|c|c|}
\hline & Open grassland & Medium encroached & Heavily encroached & $X^{2}$ & $\boldsymbol{P}$ \\
\hline Overall stems ha ${ }^{-1}$ & $157 \pm 30^{\mathrm{a}}$ & $327 \pm 39^{\mathrm{a}}$ & $1102 \pm 82^{b}$ & 51.7 & $<0.001$ \\
\hline A. drepanolobium & $128 \pm 36^{\mathrm{a}}$ & $270 \pm 29^{a}$ & $860 \pm 72^{b}$ & 41.6 & $<0.001$ \\
\hline C. africana & $150 \pm 50^{\mathrm{a}}$ & $280 \pm 71^{\mathrm{a}}$ & $540 \pm 70^{b}$ & 59.5 & $<0.001$ \\
\hline A. seyal & $0^{\mathrm{a}}$ & $240 \pm 34^{\mathrm{b}}$ & $0^{\mathrm{a}}$ & 37.3 & $<0.001$ \\
\hline A. drepanolobium stem diameter & $6.1 \pm 0.92^{\mathrm{a}}$ & $6.8 \pm 0.34^{\mathrm{a}}$ & $6.5 \pm 0.15^{\mathrm{a}}$ & 1.9 & 0.39 \\
\hline A. drepanolobium crown diameter & $2.2 \pm 0.55^{\mathrm{a}}$ & $3.1 \pm 0.18^{\mathrm{b}}$ & $3.2 \pm 0.13^{b}$ & 4.5 & 0.11 \\
\hline No of $A$. drepanolobium saplings & $180 \pm 24^{\mathrm{a}}$ & $240 \pm 37^{\mathrm{a}}$ & $780 \pm 66^{\mathrm{c}}$ & 51.7 & $<0.001$ \\
\hline No of plots with $A$. drepanolobium seedlings & $0^{\mathrm{a}}$ & $1^{\mathrm{a}}$ & $32^{\mathrm{b}}$ & 30.9 & $<0.001$ \\
\hline
\end{tabular}

Comparing heavily encroached sites between upper and lower elevations we found that lower slope areas had almost twice as many $A$. drepanolobium stems than upper slope areas $(W=669.5, P=0.0345$, Figure 3$)$. 


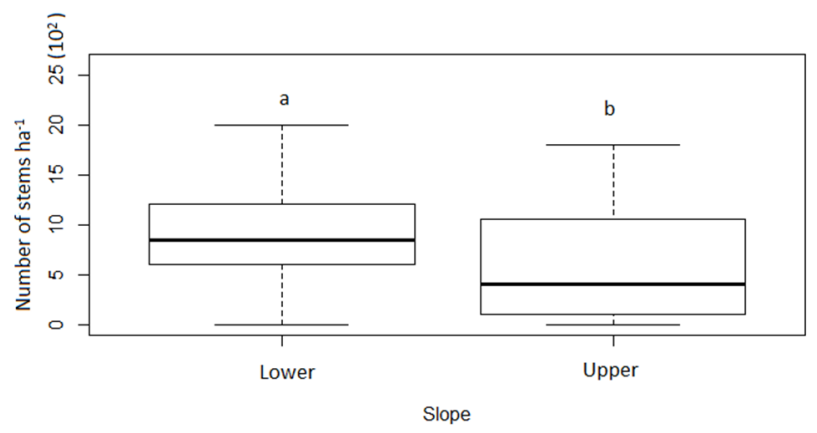

Figure 3. Median number of stems in lower slope area and higher slope areas of heavily encroached sites only, Lower plots $=1587 \pm 2.55$ masl $(n=32)$, upper plots $=1598 \pm 3.09$ masl $(n=32)$. Different letters show significant differences as per Wilcoxon signed rank test at the $95 \%$ confidence interval

Average crown diameter of $A$. drepanolobium differed significantly among encroachment categories and increased with higher encroachment $\left(X^{2}=69.08, P<0.001\right.$; Table 3$)$. The average crown diameter in heavily and medium encroached sites was about twice as high compared to open grassland (Table 3 ) while the average stem diameter did not differ across encroachment levels (Table 3 ). Sapling numbers of $A$. drepanolobium in heavily encroached sites were three times higher than those of medium encroached sites and four times higher than those of open grassland $\left(X^{2}=44.66, \mathrm{P}<0.001\right.$; Table 3$)$.

\subsection{Herbaceous Species and Woody Encroachment}

The average herbaceous species richness differed slightly $\left(F_{2,189}=18.39, P<0.001\right)$, showing on average about 1 herbaceous species more at high encroachment levels (Figure 4a).

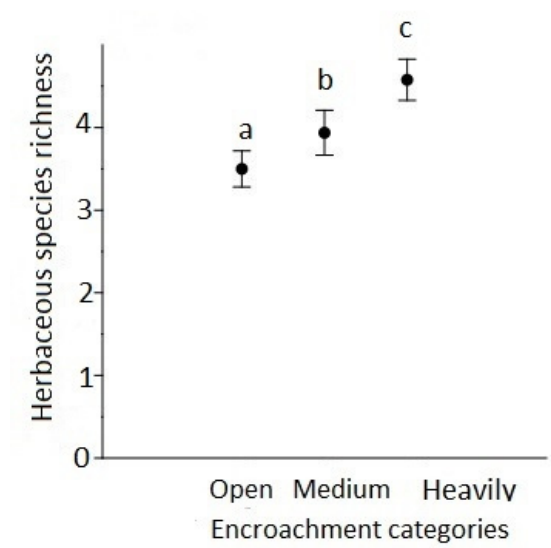

4(a)

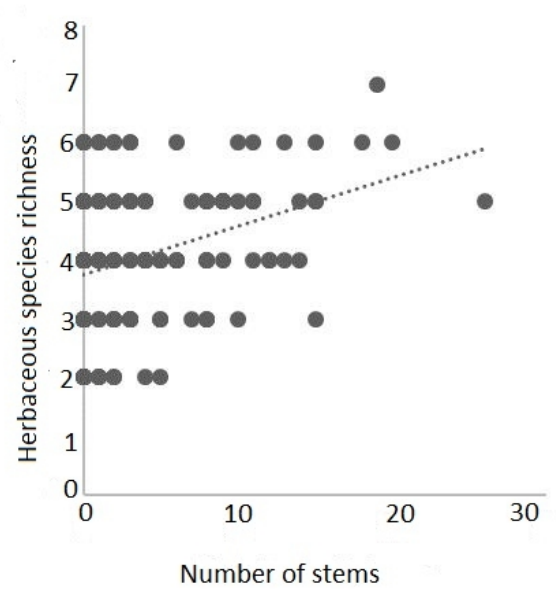

4(b)

Figure 4. a) Average ( \pm SE) herbaceous species richness across encroachment categories. Open $=$ no encroachment (grassland), medium $=$ woody cover is less than $50 \%$, heavily encroached $=$ woody plant cover is higher than $50 \%$. (b) Correlation of herbaceous species richness to the number of stems across all encroachment categories. Different letters show significant differences in means according to Dunn's test at the $95 \%$ confidence interval

The number of herbaceous species increased slightly with increasing numbers of stems $\left(r_{T}=0.24719, P<0.001\right.$, Figure $4 \mathrm{~b})$. The site similarity in terms of herbaceous species composition revealed that encroached sites are less similar compared to non-encroached sites (Figure 5).

The inter-site species composition similarity was low for heavily encroached site 1 and medium encroached site 2 on one side with open grassland sites having higher similarity on the other side (Table 4). Additionally, medium encroached site 1 had high similarity with open grassland sites (Table 4). 


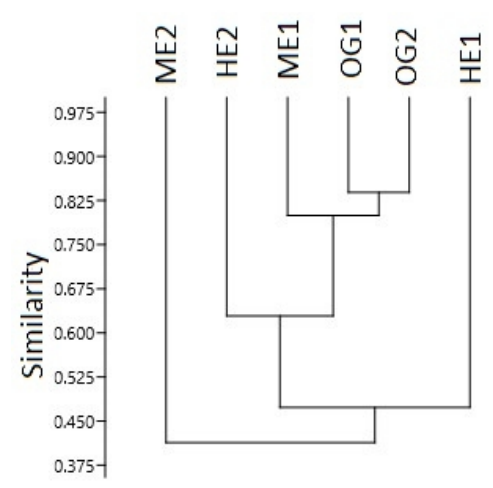

Figure 5. Dendrogram for herbaceous species composition similarity among encroached and open grassland sites, Calculated using Bray curtis similarity index. HE1 = Heavily encroached site 1, HE2 = Heavily encroached site 2, ME1 = Medium encroached site 1, ME2 = Medium encroached site 2, OG1 = Open grassland site 1 and

OG2 $=$ Open grassland site 2

Table 4. Bray Curtis similarity distances along encroachment categories, HE1 = Heavily encroached site 1, HE2= Heavily encroached site 2, ME1= Medium encroached site 1, ME2 = Medium encroached site 2, OG1 = Open grassland site 1 and OG2 = Open grassland site 2

\begin{tabular}{lllllll}
\hline & HE1 & HE2 & ME1 & ME2 & OG1 & OG2 \\
\hline HE1 & 1 & & & & & \\
HE2 & 0.473 & 1 & & & & \\
ME1 & 0.331 & 0.629 & 1 & 1 & & \\
ME2 & 0.268 & 0.368 & 0.413 & 0.269 & 1 & 1 \\
OG1 & 0.192 & 0.452 & 0.729 & 0.353 & 0.839 & \\
\hline
\end{tabular}

In total, herbaceous species composition in heavily encroached sites are related to medium encroached sites by $47.9 \%$, and to open grassland by $34 \%$. However, herbaceous species in medium encroached sites are related to open grassland by $56 \%$.

The average proportion of bare ground in open grassland was three times lower in non encroached areas compared to that of medium encroached sites and six times lower than heavily encroached sites $\left(X^{2}=62.98, P<0.001\right.$, Figure 6). Furthermore, the proportion of bare ground increased with increasing number of woody plant stems $\left(\mathrm{r}_{\mathrm{T}}=\right.$ $0.38504, P<0.001)$.

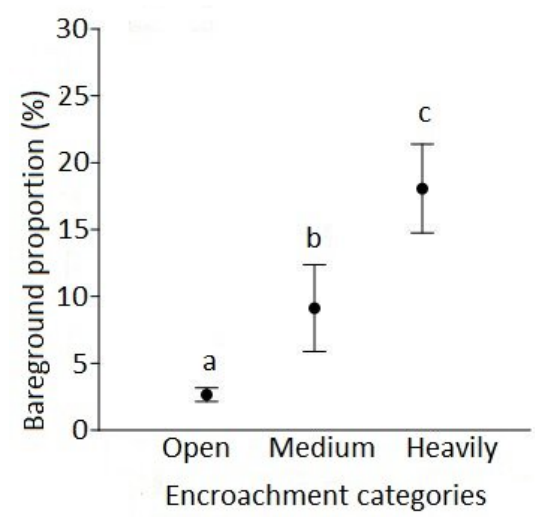

Figure 6. Average $( \pm$ SE) proportion of bare ground across encroachment categories. Open grassland $=$ sites with no encroachment, medium encroached sites = sites with less than $50 \%$ of woody cover, heavily encroached sites $=$ sites with more than $50 \%$ of woody cover. Different letters show significant differences according to Dunn's post hoc test at $95 \%$ confidence level 


\subsection{Herbivore Species and Woody Plant Encroachment}

Generally, there were slightly more herbivore species found in open grassland and medium encroachment encroached sites than in heavily encroached sites i.e. on average one (1) species only $\left(X^{2}=11.08, P=0.002\right.$, Figure 7). Generally, the number of observed herbivore species decreased with an increase in the number of woody stems $\left(r_{I}=-0.204, P<0.001\right)$.

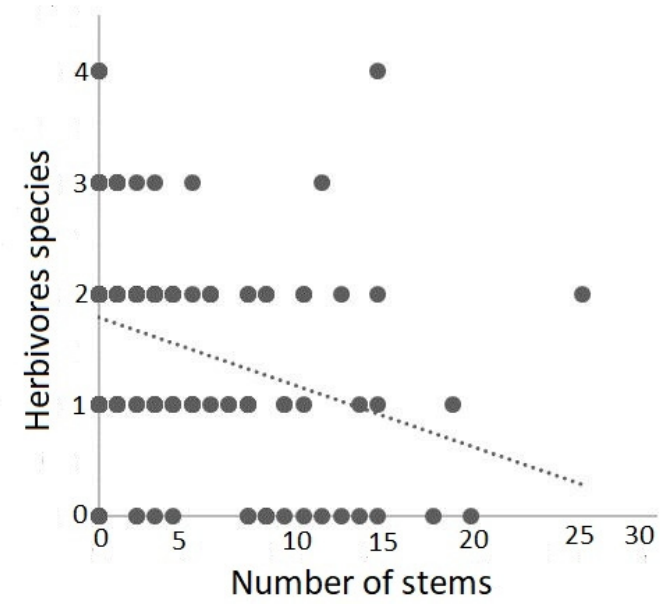

$7(\mathrm{a})$

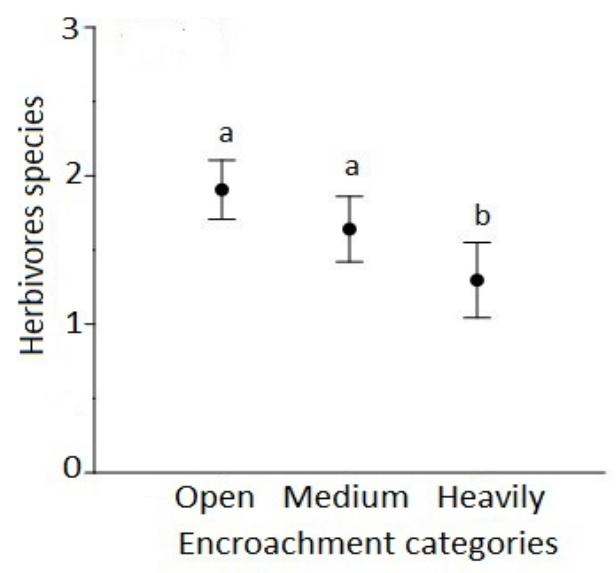

7(b)

Figure 7. (a) Average number of herbivores species along encroachment categories (b) shows a correlation of herbivores species with an increasing number of stems. Open grassland $=$ sites with no encroachment, medium encroached sites $=$ sites with less than $50 \%$ of woody cover, heavily encroached sites $=$ sites with more than $50 \%$ of woody cover. Different letters show significant differences according to Dunn's test at the $95 \%$ Confidence Interval

Table 5. The proportion of plots within which signs of different herbivore species/guilds were found $(n=64$ per encroachment category) across each encroachment category. Different letters show significant differences as per Dunn's post hoc test at the $95 \%$ confidence interval $(\mathrm{N}=192)$

\begin{tabular}{|c|c|c|c|c|c|}
\hline & Non encroached & Medium encroached & Heavily encroached & $X^{2}$ & $P$ \\
\hline Grazers & $0.63^{\mathrm{a}}$ & $0.19^{\mathrm{b}}$ & $0.4^{\mathrm{c}}$ & 18.28 & $<0.001$ \\
\hline Browsers & $0.13^{\mathrm{a}}$ & $0.17^{\mathrm{a}}$ & $0.19^{\mathrm{a}}$ & 0.40 & 0.61 \\
\hline Mixed feeders & $0.30^{\mathrm{a}}$ & $0.31^{\mathrm{a}}$ & $0.30^{\mathrm{a}}$ & 0.03 & 0.98 \\
\hline Predators & 0.00 & 0.00 & 0.03 & & \\
\hline \multicolumn{6}{|l|}{ Wildlife species: } \\
\hline Loxodonta africana & $0.16^{\mathrm{a}}$ & $0.19^{\mathrm{a}}$ & $0.20^{\mathrm{a}}$ & 0.22 & 0.78 \\
\hline Syncerus caffer & $0.39^{\mathrm{a}}$ & $0.13^{\mathrm{b}}$ & $0.19^{\mathrm{b}}$ & 7.36 & 0.001 \\
\hline Giraffa camelopardalis & $0.13^{\mathrm{a}}$ & $0.16^{\mathrm{a}}$ & $0.14^{\mathrm{a}}$ & 0.09 & 0.88 \\
\hline Equus quagga & $0.30^{\mathrm{a}}$ & $0.08^{\mathrm{b}}$ & $0.09^{\mathrm{b}}$ & 5.25 & 0.002 \\
\hline Connochaetes taurinus & $0.03^{\mathrm{a}}$ & $0.03^{\mathrm{a}}$ & $0.22^{\mathrm{b}}$ & 4.47 & $<0.001$ \\
\hline Aepyceros melampus & $0.13^{\mathrm{a}}$ & $0.17^{\mathrm{a}}$ & $0.11^{\mathrm{a}}$ & 0.40 & 0.56 \\
\hline Madoqua sp & $0^{\mathrm{a}}$ & $0^{\mathrm{a}}$ & $0.05^{\mathrm{b}}$ & 0.28 & 0.005 \\
\hline
\end{tabular}

Generally, there was a trend that grazer species (wildebeest, zebra, buffalo) were negatively correlated with an increasing number of woody stems $\left(r_{T}=-0.150, P=0.002\right.$, table 5), browsers (giraffe) were positively correlated with an increasing number of stems $\left(r_{T}=0.05, P=0.280\right)$ and mixed feeders (elephant and impala) were negatively correlated with an increasing number of stems $\left(r_{T}=-0.060, P=0.200\right)$. The few signs of lion $(P$. leo $)$ that we found were slightly positively correlated with increased numbers of stems $\left(r_{I}=0.120, P=0.010\right.$, table 5$)$. 


\section{Discussion}

\subsection{Change in Woody Plant Cover}

The south and west of Maswa Game Reserve have experienced decreasing woody plant cover, similar to trends identified by Homewood et al. (2001) and Dempewolf (2007) for savanna systems in Serengeti. A decrease in woody plant cover is often associated with storing fire intensity (Dempewolf, 2007) as well as an increase in local human population (Venter et al., 2018). Hence, our results conform with other studies in the Serengeti ecosystem (Makacha et al., 1982), where a local increase in human populations has led to pressure over natural resources through, e.g., land for settlement, cultivation, illegal fire wood harvesting, as well as weak law enforcement (Venter et al., 2018). We found a high woody plant encroachment in the eastern side of the Maswa Game Reserve, i.e., close to the boundary of Serengeti National Park, and in the middle of the Maswa Game Reserve. Similar patterns of increase in woody plants has been reported by Homewood et al. (2001) in Serengeti ecosystem. Despite the general change in woody vegetation classes, only shrubland had the net gain i.e. increase in woody cover and was highly pronounced in different areas of the Maswa Game Reserve from 1986 to 2018.

\subsection{Acacia Drepanolobium and Commiphora Africana Are the Main Contributors to Bush Encroachment}

Our results suggest that $A$. drepanolobium is a major encroaching species, dominating black cotton soil areas, followed by C. africana. Similar patterns have been found elsewhere (Angassa \& Oba, 2007; Lemenih, Gure, \& Angassa, 2011; Okello, 2007). Acacia seyal, in contrast, was a minor encroaching species. Commiphora africana was reported to encroach in other parts of Africa, while A. seyal was not found to be an encroaching species (Lemenih et al., 2011). The number of stems per hectare for all tree species combined in heavily encroached sites was three times higher than that of medium encroached sites and was seven times higher than that of open grassland. Despite the differences in the number of woody plants along the encroachment intensity gradient, there were abundant saplings of $A$. drepanolobium in all encroachment levels, highlighting that the potential of further encroachment of these young tree/shrub population is high. Similarly, high numbers of A. drepanolobium saplings were reported by Lemenih et al. (2011).

Such variation in woody cover affects wildlife species movement and habitat use, particularly in encroached sites (Smit \& Prins, 2015), and impacts the ecological condition of grassland ecosystems (Yusuf, Treydte, Demissew, $\&$ Woldu, 2011) as well as jeopardizing tourism activities (Smit \& Prins, 2015). Heavily and medium encroached sites had both higher crown cover and higher seedling occurrence, which is in line with this result, Lemenih et al. (2011) and indicates that even densely populated woody vegetation patches have not reached the point of selfthinning. In our study, open grassland lacked any tree seedlings. This could be a result of the higher competition between woody and grassy vegetation for water resources due to a healthier grass cover in open grassland than in encroached sites (Morrison, Holdo, Rugemalila, Nzunda, \& Anderson, 2019). Furthermore, mammal trampling and herbivore predation might also have suppressed tree seedling establishment in areas easily accessed by wildlife such as open grassland (Angassa \& Oba, 2007).

\subsection{Factors Contributing to Woody Plant Spread and Encroachment}

We found more trees per plot in lower slope areas than upper slope areas, which highlights the role of landscape topography in the encroachment process of $A$. drepanolobium. Initial woody plant encroachment has been found to be more significant in drainage areas within the Serengeti ecosystem (Reed, Anderson, Dempewolf, Metzger, $\&$ Serneels, 2009). Furthermore, lowland sites have high silt and clay content, and as these soils dry, they fracture and put stress on woody plants. However, A. drepanolobium has been shown to cope with this stress, whereas other woody plant species seem to be maladapted there (Kimaro et al., in press; Pringle, Prior, Palmer, Young, \& Goheen, 2016). In other parts of the world, water has been suggested as an important seed dispersal agent of various woody plant species causing woody plant encroachment (Archer et al., 2017; Lemenih et al., 2011).

Additionally, in agreement with other studies, our result suggests that woody plant encroachment may be highest in areas with low fire frequency and intensity. With increasing bare ground proportions and a reduced herbaceous layer, as we found in our encroached sites, fire frequency and fire intensity also decrease (Reed et al., 2009). Reduced fire intensity facilitates woody plant encroachment by increasing seedling and sapling establishment (Estes, Raghunathan, \& Vleck, 2008). Secondly, fire significantly reduces the abundances of symbiont ants living on and in A. drepanolobium (Sensenig et al., 2017), which we also observed in our study. Reduced ant abundance weakens A. drepanolobium's defense against herbivores and increases this species' vulnerability to herbivory (Sensenig et al., 2017), which consecutively can suppress further bush encroachment. In Maswa Game Reserve, fire has been perceived to be destructive to habitat and thus chase away mammalian herbivore species, which resulted in abandonment of prescribed burning as a management tool in Maswa in 2008. The consequences of 
preventing fire has been woody plant encroachment in other parts of Africa (Lemenih et al., 2011; Yusuf et al., 2011).

The presence of mega-herbivores such as elephants may further contribute to the spreading of $A$. drepanolobium (Brahmachary, 1980; Harich et al., 2016; Nchanji \& Plumptre, 2003). We found that, on average, one elephant dung pile carries $204 \pm 14.84$ seeds of $A$. drepanolobium (un-published data); a similar value of woody plant seeds per elephant dung was found in Congo (Brahmachary, 1980). Furthermore, from our complementary experiment and field observations, $A$. drepanolobium seeds are capable of germinating in zebra, elephant and buffalo dung (Kimaro et al., in press). When elephants shift from grazing to browsing in the hot-dry season (August-October) in Maswa Game Reserve, they feed mainly on A. drepanolobium trees, including their pods, thereby spreading the seeds (Birkett, 2002). In contrast, elephants have also been shown to open up bushy and dense wooded landscape (Haynes, 2012). Hence, poaching of elephants could contribute to increases in woody cover as elephants tend to push over large trees and, thereby, open up woody areas (Dempewolf, 2007; Stevens, Lehmann, Murphy, \& Durigan, 2016). Over the last decade, Maswa Game Reserve has experienced rampant elephant poaching for ivory (Kideghesho, 2016) that has led to decreases in the local elephant population and has probably shifted their habitat to safer sites inside the Serengeti National Park. Such shifts in habitat and decreases in elephant densities can reduce browsing pressure and, consequently, enhance woody plants and the directional succession towards bushy vegetation (Dempewolf, 2007).

\subsection{Woody Plant Encroachment Affecting Herbaceous Species and Bare Soil}

In our study, encroached sites had slightly higher species richness of herbaceous plants but a high bare soil proportion. A study from southern Ethiopia reported a negative correlation between bush and grass cover, as well as a positive correlation between bare soil and bush cover (Angassa \& Oba, 2007). In agreement with our findings, (Dharani, 2006) indicated that $A$. drepanolobium covered sites harbor more species of herbaceous plants as it offers protection against herbivory. Open grassland sites had the highest scores of Bray Curtis similarity index (84\%), a pattern that contrasts medium and heavily encroached sites similarities. The high similarity of open grassland communities in our study indicated that encroached sites promote different herbaceous species assemblages, which could also be attributed to the $\mathrm{N}$-fixing capacities of this encroacher Acacia species, which might promote grasses dependent on high soil nutrient availability (Sun et al., 2016).

\subsection{Woody Plant Encroachment and Mammalian Herbivore Guilds}

We found that grazers occurred slightly more often in open grassland than in medium and heavily encroached sites, which is similar to Okello (2007), who reported low mammalian herbivore numbers in A. drepanolobiumdominated vegetation. Both access as well as forage availability and quality were probably reduced in our bushencroached sites, which was also found by Yassin (2019), for a bush encroached system in southern Ethiopia. In our study, browser occurrence was positively correlated with woody plant encroachment levels, which confirms studies by Smit \& Prins, (2015) in South African savannas. We found only giraffes, to be particular browsing species that seemed to prefer bush-encroached sites. Giraffes have been shown to prefer feeding on a variety of Acacia species (Mahenya, 2016; Blomqvist, 2007); hence, they might even benefit from bush-encroached sites. However, our indirect observations were just a snapshot of the area within the wet season. Since this area is also an important great migration resting area (Makacha et al., 1982), herbivore abundances might change strongly over season. In additon, studies including camera traps and direct observation transects would help obtain a more detailed picture on how bush encroachment in the Serengeti system affects mammalian herbviore assemblages. Generally, we found fewer dung and footprint signs of herbivores in encroached sites than in open grassland. Lower herbivore species activities and loss of herbivore species in encroached sites may also be a consequence of an increased landscape of fear due to a higher predation risk, particularly of ambush predators (Pringle, 2018).

\section{Conclusion}

We found a significant change in woody plant cover in Maswa Game Reserve, particularly in the middle of the reserve between the years 1986 and 2018. While Maswa areas bordering local communities have experienced a decrease in woody cover, probably due to intense wood harvesting and weak law enforcement. Acacia drepanolobium was the main encroaching species, followed by $C$. africana, while $A$. seyal encroachment was least severe. Furthermore, our finding of many seedlings and saplings suggests that woody plant encroachment is ongoing and, hence, with time more woody thickening will be realized in open grassland. We proposed that fire exclusion in Maswa, rainfall water runoff, and dispersal of the seeds by mega-herbivores may have been the main drivers for the spread of $A$. drepanolobium. We further found that encroachment of $A$. drepanolobium results in lower herbaceous cover and an increase in bare ground cover and, consecutively, has led to low medium sized mammalian herbivore species numbers. Mega-herbivores such as African elephant slow down growth of bushes 
and open up wooded area thus reducing wood plant encroachment as it reduces dense standing brush due to higher browsing pressure during the dry season. We suggest that fire regimes should be taken up to suppress the ongoing encroachment processes while strongly encroached sites might need mechanical intervention to control dense vegetation. This emphasis is on fire, particularly prescribed fire as a management tool of vegetation in Savanna ecosystem. We conclude that, woody plant encroachment is a result of different factors such as fire, megaherbivores, and topology that may interactively trigger woody plant encroachment in Savanna ecosystem.

\section{Funding}

This study was funded by the Government of Tanzania through the Nelson Mandela African Institution of Science and Technology (NM-AIST) under CREATES scholarship program for MSc candidates. H.S. Kimaro was supported by MSc grant from CREATES, Rufford Small Grants (23703-1) and IDEA WILD.

\section{Acknowledgements}

In addition to thanking the funders, we acknowledge support during field work from Friedkin's Conservation Fund and Idea Wild Organization. We acknowledge valuable comments, support and contributions from M. Anderson, O. Nzunda, D. W. Williamson and E. Kiwhele. Furthermore, the study has been possible due to keen support from Tanzania Wildlife Research Institute (TAWIRI), Tanzania Wildlife Management Authority (TAWA). The field work was strongly supported by the commitment of J. H. Kimaro, R. E. Ishengoma, M. Maganga, M. Mtende, H. Adam and W. Alli. The paper has been grammatically reviewed by Jane Petring from US Department of State and English Language Fellow to College of African Wildlife Management, Mweka.

\section{Conflict of interests}

The authors declare that there is no conflict of interests regarding the publication of this paper.

\section{References}

Abate, T., \& Angassa, A. (2016). Conversion of savanna rangelands to bush dominated landscape in Borana, Southern Ethiopia. Ecological Processes, 5(1), 1-18.

Angassa, A., \& Oba, G. (2007). Effects of management and time on mechanisms of bush encroachment in southern Ethiopia. African Journal of Ecology, 46, 186-196.

Archer, S. (1995). Tree-grass dynamics in a Prosopis-thornscrub savanna parkland: Reconstructing the past and predicting the future. Ecoscience, 2(1), 83-99.

Archer, S. R., Andersen, E. M., Predick, K. I., Schwinning, S., Steidl, R. J., \& Woods, S. (2017). Woody plant encroachment: Causes and consequences. In Rangeland Systems (p. 60). Springer.

Van Auken, O. W. (2000). Shrub invasions of North American semiarid grasslands. Annual Review of Ecology and Systematics, 31(1), 197-215.

Van Auken, O. W. (2009). Causes and consequences of woody plant encroachment into western north American grasslands. Journal of Environmental Management, 90(10), 2931-2942.

Bacaro, G., Rocchini, D., Diekmann, M., Gasparini, P., ..., \& Chiarucci, A. (2015). Shape matters in sampling plant diversity: Evidence from the field. Ecological Complexity, 24, 37-45.

Bartzke, G. S., Ogutu, J. O., Mukhopadhyay, S., Mtui, D., Dublin, H. T., \& Piepho, H. P. (2018). Rainfall trends and variation in the Maasai Mara ecosystem and their implications for animal population and biodiversity dynamics. PLoS ONE, 13(9).

Beltrán, A. P. R. (2015). Mapping of vegetation types and bush encroachment in Namibia. University of Twente Faculty of Geo-Information and Earth Observation (ITC).

Birkett, A. (2002). The impact of giraffe, rhino and elephant on the habitat of a black rhino sanctuary in Kenya. African Journal of Ecology, 40(3), 276-282.

Blomqvist, P. A., \& Renberg, L. (2007). Feeding behaviour of Giraffe (Giraffa camelopardalis) in Mokolodi Reserve. Botswana: University of Uppsala. Minor Field Study, 1653-5634.

Bond, W. J. (2008). What limits trees in C4 grasslands and savannas? Annual Review of Ecology, Evolution, and Systematics, 39, 641-659.

Brahmachary, R. L. (1980). On the germination of seeds in the dung balls of the African elephant in the Virunga National Park. Revue d'Ecologie (Terre \& Vie), 34(1), 139-142. 
Buckland, S. T., Borchers, D. L., Johnston, A., Henrys, P. A., \& Marques, T. A. (2007). Line transect methods for plant surveys. Biometrics, 63(4).

Chami, A. (2018). Women participation in cotton farming in Simiyu region, Tanzania: Undefined paradoxical praxis. Universal Journal of Agricultural Research, 1(2), 1-9.

Congalton, R., \& Green, K. (1999). Assessing the accuracy of remotely sensed data. Principles and practices. Lewis Publishers, Boca Raton.

Damgaard, C. (2014). Estimating mean plant cover from different types of cover data: A coherent statistical framework. Ecosphere, 5(2), 1-7.

Dempewolf, J. (2007). Fire dynamics and woody cover changes in the Serengeti-Mara ecosystem 2000 to $2005-A$ Remote sensing approach (Doctoral dissertation). University of Maryland.

Dharani, N. (2006). Field Guide to Acacias of east Africa. Nairobi: Struik.

Eldridge, D. J., Bowker, M. A., Fernando, M., Roger, E., Reynolds, J., \& Whitford, W. G. (2011). Impacts of shrub encroachment on ecosystem structure and functioning: Towards a global synthesis. Ecology Letters, 14(7), 709-722.

Estes, A. R. D., Raghunathan, T. E., \& Vleck, D. Van. (2008). The impact of horning by wildebeest on woody vegetation of the Serengeti ecosystem. The Journal of Wildlife Management, 72(7), 1572-1578.

Exelis Visual Information Solutions. (2015). Exploring ENVI. Boulder, Colorado.

Hammer, Ø., Harper, D. A., \& Ryan, P. D. (2001). PAST: Paleontological Statistics Software Package for education and data analysis. Palaeontologia Electronica, 4(1).

Harich, F. K., Treydte, A. C., Ogutu, J. O., Roberts, J. E., \& Savini, T. (2016). Seed dispersal potential of Asian elephants. Acta Oecologica, 77, 144-151.

Jangu, M. H. (2012). Healing environmental harms: Social change and Sukuma traditional medicine on Tanzania' $s$ extractive e frontier. University of Michigan.

Jurena, P. N., \& Van Auken, O. W. (1998). Woody plant recruitment under canopies of two Acacias in a southwestern Texas shrubland. The Southwestern Naturalist, 43(2), 195-203.

Keeping, D., \& Pelletier, R. (2014). Animal density and track counts: Understanding the nature of observations based on animal movements. PloS One, 9(5), 1-11.

Kgosikoma, O. E., \& Mogotsi, K. (2013). Understanding the causes of bush encroachment in Africa: The key to effective management of savanna grasslands. Tropical Grasslands-Forrajes Tropicales, 1(2), 215-220.

Khavhagali, V. P., \& Bond, W. J. (2008). Increase of woody plants in savannah ecosystems. Newsl. Grassland Soc. Southern Africa, 8(2), 21-24.

Kideghesho, J. R. (2016). The Elephant poaching crisis in Tanzania: A need to reverse the trend and the way forward.

Kuemmerle, T., Perzanowski, K., Chaskovskyy, O., Ostapowicz, K., \& Radeloff, V. C. (2010). European bison habitat in the Carpathian Mountains. Biol. Conserv., 143, 908-916.

Lemenih, M., Gure, A., \& Angassa, A. (2011). Impact of Acacia drepanolobium (an invasive woody species) on gum-resin resources and local livelihood in Borana, southern Ethiopia. Tropical and Subtropical Agroecosystems, 14(3), 13.

Mahenya, O. J. (2016). Browsing by giraffe in heterogeneous savanna. Doctoral dissertation, Inland Norway University.

Makacha, S., Msingwa, M. J., \& Frame, G. W. (1982). Threats to the Serengeti herds. Oryx, 16(5), 437-444.

Monteiro, E. D. C., Burak, D. L., Cunha, A. D. M., \& Passos, R. R. (2018). Visual assessment of pasture degradation: Validation by ground cover and seasonal variation. Revista Ciência Agronômica, 49(1), $174-$ 182 .

Morrison, T. A., Holdo, R. M., Rugemalila, D. M., Nzunda, M., \& Anderson, T. M. (2019). Grass competition overwhelms effects of herbivores and precipitation on early tree establishment in Serengeti. Journal of Ecology, 107(1), 216-228. 
Nchanji, A. C., \& Plumptre, A. J. (2003). Seed germination and early seedling establishment of some elephantdispersed species in Banyang-Mbo Wildlife Sanctuary, south-western Cameroon. Journal of Tropical Ecology, 19(3), 229-237.

Niboye, E. P. (2010). Vegetation cover changes in Ngorongoro Conservation Area from 1975 to 2000: The importance of remote sensing images. The Open Geography Journal, 3(14), 15-27.

Okello, B. D. (2007). Effects of herbivores on the fire and harvesting population dynamics of Acacia drepanolobium Sjoestedt in Laikipia, Kenya. University of KwaZulu-Natal.

Pfeffer, S. (2016). Comparison of three different indirect methods to evaluate ungulate population densities. Swedish University of Agricultural Science.

Pringle, R. M. (2018). Megaherbivores homogenize the landscape of fear. Current Biology, 28(15), R835-R837.

Pringle, Ro. M., Prior, K. M., Palmer, T. O. D. D. M., Young, T. R. P., \& Goheen, J. A. R. G. (2016). Large herbivores promote habitat specialization and beta diversity of African savanna trees. Ecological Society of America, 97(10), 2640-2657.

Ratajczak, Z., Nippert, J. B., \& Collins, S. L. (2012). Woody encroachment decreases diversity across north American grasslands and savannas. Ecological Society of America, 93(3), 441-448.

Reed, D. N., Anderson, T. M., Dempewolf, J., Metzger, K., \& Serneels, S. (2009). The spatial distribution of vegetation types in the Serengeti ecosystem: The influence of rainfall and topographic relief on vegetation patch characteristics. Journal of Biogeography, 36(4), 770-782.

Saatkamp, A., Poschlod, P., \& Venable, D. L. (2014). The functional role of soil seed banks in natural communities. In The Ecology of Regeneration in Plant Communities (3rd ed., pp. 263-295). CAB International 2014.

Sea, W. B., \& Hanan, N. P. (2012). Self-thinning and tree competition in savannas. BIOTROPICA, 44(2), 189196.

Sensenig, R. L., Kimuyu, D. K., Guajardo, J. C. R., Veblen, K. E., Riginos, C., \& Young, T. P. (2017). Fire disturbance disrupts an acacia ant-plant mutualism in favor of a subordinate ant species. Ecological Society of America, 98(5).

Smit, I. P. J., \& Prins, H. H. T. (2015). Predicting the effects of woody encroachment on mammal communities, grazing biomass and fire frequency in African savannas. PLoS ONE, 10(9), 1-16.

Stevens, N., Lehmann, C. E. R., Murphy, B. P., \& Durigan, G. (2016). Savanna woody encroachment is widespread across three continents. Global Change Biology, 23(1), 235-244.

Sun, X., Yu, K., Shugart, H. H., \& Wang, G. (2015). Species richness loss after nutrient addition as affected by N: $\mathrm{C}$ ratios and phytohormone GA3 contents in an alpine meadow community. Journal of Plant Ecology, 9(2), 201-211.

TAWA. (2018). Tanzania Wildlife Management Authority (TAWA): Maswa Game Reserve. Retrieved October 7 , 2018, from http://www.tawa.go.tz/conservation/protected-areas/game-reserves/maswa/

Tefera, S., Dlamini, B. J., \& Dlamini, A. M. (2008). Dynamic of savanna in Swaziland: Encroachment of Wood plant in relation to land use and soil classes and indigeneous knowledge on plant utilization. Research Journal of Botany, 3(2), 49-64.

Treydte, A. C., Heitko, I. M. A., Prins, H. H. T., \& Ludwig, F. (2007). Trees improve grass quality for herbivores in African savannas. Perspectives in Plant Ecology, Evolution and Systematics, 8(4), 197-205.

Tsegaye, D., Moe, S. R., Vedeld, P., \& Aynekulu, E. (2010). Land-use/cover dynamics in Northern Afar rangelands, Ethiopia. Agric Ecosyst Environ, 139, 174-180.

URT. (2017a). Environmental impact statement for the proposed climate resilient water supply project in Busega, Bariadi and Itilima districts, Simiyu region (Vol. 255).

URT. (2017b). Simiyu region investment guide.

Venter, Z. S., Cramer, M. D., \& Hawkins, H. J. (2018). Drivers of woody plant encroachment over Africa. Nature Communications, 9(1), 1-7.

Ward, D. (2005). Do we understand the causes of bush encroachment in African savannas? African Journal of Range and Forage Science, 22(2), 101-105. 
Wonga, C. C., \& Wilson, J. R. (1980). Effects of shading on the growth and nitrogen content of Green Panic and Siratro in pure and mixed swards defoliated at two frequencies. Australian Journal of Agricultural Research, 31(2), 269-285.

Yachi, S., \& Loreau, M. (1999). Biodiversity and ecosystem productivity in a fluctuating environment: The insurance hypothesis. PNAS (Proc. Natl. Acad. Sci.), 96.

Yassin, I. (2019). Bush Encroachment in Borana Rangeland in the case of Southern Ethiopia: Causes, Impacts and Management Implications. International Journal of Agriculture Innovations and Research, 7(4).

Yusuf, H., Treydte, A. C., Demissew, S., \& Woldu, Z. (2011). Assessment of woody species encroachment in the grasslands of Nechisar National Park, Ethiopia. African Journal of Ecology, 49, 397-409.

\section{Copyrights}

Copyright for this article is retained by the author(s), with first publication rights granted to the journal.

This is an open-access article distributed under the terms and conditions of the Creative Commons Attribution license (http://creativecommons.org/licenses/by/4.0/). 